\begin{tabular}{|l|l|l|}
\hline \multicolumn{2}{|c|}{ PublisherInfo } \\
\hline \hline PublisherName & $:$ & BioMed Central \\
\hline \hline PublisherLocation & $:$ & London \\
\hline \hline PublisherImprintName & $:$ & BioMed Central \\
\hline \hline
\end{tabular}

\title{
Cartilage protection by IL-4 targeted gene therapy in CIA
}

\begin{tabular}{|l|l|l||}
\hline \multicolumn{2}{|c||}{ ArticleInfo } \\
\hline \hline ArticleID & $:$ & 40 \\
\hline \hline ArticleDOI & $:$ & $10.1186 /$ ar-1999-66747 \\
\hline \hline ArticleCitationID & $:$ & 66747 \\
\hline \hline ArticleSequenceNumber & $:$ & 36 \\
\hline \hline ArticleCategory & $:$ & Paper Report \\
\hline \hline ArticleFirstPage & $:$ & 1 \\
\hline \hline ArticleLastPage & $:$ & 3 \\
\hline \hline & & RegistrationDate : 1999-11-11 \\
ArticleHistory & $:$ & OnlineDate \\
\hline \hline ArticleCopyright & $:$ & Current Science Ltd1999-11-11 \\
\hline \hline ArticleGrants & $:$ & \\
\hline \hline ArticleContext & $:$ & 130752211 \\
\hline \hline
\end{tabular}




\section{Keywords}

Cartilage, collagen-induced arthritis, gene therapy, IL-4

\section{Context}

Collagen-induced arthritis (CIA) in the mouse results in a symmetrical erosive arthritis of peripheral joints, characterized by massive inflammatory infiltrates and synovial hyperplasia. As in rheumatoid arthritis, cytokine imbalance drives the molecular pathology of joint destruction, with IL-1 and tumour necrosis factor (TNF) playing key, though somewhat distinct, roles: IL-1 inhibition results in chondroprotection, while TNF inhibition is anti-inflammatory. Anti-inflammatory cytokines, notably IL-4 and IL-10, that can inhibit or reverse proinflammatory mediator-induced activation of target cells, do not rise to levels necessary for amelioration of disease. Therefore the administration of these agents is currently under vigorous investigation. In vivo, cytokines act locally, and systemic administration of anti-inflammatory cytokines can limit their efficacy. Moreover, systemic administration of IL-4 can result in unwanted side effects, including immunosuppression and atopy in animal models of disease. Consequently, targeted gene transfer using viral vectors is becoming an important investigational delivery tool for a variety of autoinflammatory states. To examine the effects of targeted IL-4 gene transfer to the affected knee joints of CIA mice on the molecular pathology of disease using an adenovirus vector system.

\section{Significant findings}

A single intra-articular injection of recombinant control vector or IL-4 expressing (Ad5E1 mIL-4) adenovirus was given prior to disease onset in CII-immunized and naive DBA-1 mice. IL-4 protein, which was not detected in untreated and control vector treated animals, was observed in the joints of Ad5E1 mIL-4-treated animals 7 days post injection of virus. Both Ad5E1 mIL-4 and control vector administration had proinflammatory effects (increasing leukocyte infiltrates as well as the severity and frequency of arthritis) in CII-treated animals. Additionally, Ad5E1 mIL-4, but not control vector administration, induced leukocyte infiltrates in naive animals although no frank arthritis was noted. Although proteoglycan depletion, as measured by safranin O staining, was not influenced by Ad5E1 mIL-4 administration, histologic analysis revealed that cartilage erosions were profoundly inhibited in Ad5E1 mIL-4-treated animals. Accordingly, IL-4 overproduction in these animals significantly reduced chondrocyte death, blocked the pathologic loss of proteoglycan synthesis, as well as inhibited expression of VDIPEN, a marker of matrix metalloproteinase (MMP) mediated aggrecan cleavage. Several key proinflammatory mediators were reduced in Ad5E1 mIL-4-treated animals relative to controls, including 
IL-1 $\mathrm{I} \pm$ mRNA levels in both the synovium and articular cartilage, as well as IL-1 $\hat{\mathrm{I}} \pm$ protein, MMP-3 and TNF-I ${ }^{2}$ mRNA levels, and nitric oxide (NO) production in the synovium. No significant changes were noted in IL-1Ra mRNA levels. In vector control treated animals, large numbers of exudate and cartilage adherent neutrophils were present in the joint space. In Ad5E1 mIL-4-treated animals, neutrophil counts were greatly diminished in the exudates, and no cartilage-adherent neutrophils were observed.

\section{Comments}

The dichotomy of function among proinflammatory cytokines on the molecular pathology of arthritis is becoming dogma. This study, by clearly delineating the proinflammatory and chondroprotective effects of IL-4 adenoviral gene therapy, provides compelling evidence that anti-inflammatory cytokines also have discrete roles in the molecular pathology of the arthritic process. The CIA model is distinguished by the highly erosive nature of disease progression. As stated by the authors, inhibition of joint erosion is of paramount importance in human disease state management. These facts underlie the importance of the preclinical data presented in this work as questions of the most appropriate vehicles and genes to be used for gene therapy in human arthritides are debated and tested.

\section{Methods}

DBA-1 mice were immunized with bovine type II collagen in complete Freund's adjuvant between 10 and 12 weeks of age. Just prior to the usual time of onset of arthritis mice were scored visually and, in those without signs of arthritis, 1 or 10 million plaque forming units of either an IL-4 expressing (Ad5E1 mIL-4) or empty control vector-containing recombinant replication-deficient adenovirus was injected intra-articularly into the knee joint. Seven days after intra-articular injection, mice were killed, the severity of arthritis assessed and molecular and histopathologic samples collected. Cytokines were measured in patella washouts by ELISA. Proteoglycan depletion was determined using safranin O staining and proteoglycan synthesis was determined by interphalangeal injection of radiolabelled sulfate, $2 \mathrm{~h}$ prior to joint dissection. Proteoglycan degradation was measured as a function of the appearance of the degradation-specific neoantigen VDIPEN using immunohistochemistry (IHC). Neutrophil influx in knee joint sections was measured by IHC; nitrite levels in washout from cultures of patella tissue were measured using the Griess reaction.

\section{References}

1. Lubberts E, Joosten LA, van Den Bersselaar L, Helsen MM, Bakker AC, van Meurs JB, Graham FL, Richards CD, van Den Berg WB: Adenoviral vector-mediated overexpression of IL-4 in the knee joint of mice with collagen-induced arthritis prevents cartilage destruction. J Immunol. 1999, 163: 4546-4556. 